\title{
Transition and Turbulence Modeling for Blunt-Body Wake Flows
}

\author{
Robert P. Nance* \\ North Carolina State University, Raleigh, North Carolina \\ Thomas J. Horvath ${ }^{\dagger}$ \\ NASA Langley Research Center, Hampton, Virginia \\ H. A. Hassan ${ }^{\ddagger}$ \\ North Carolina State University, Raleigh, North Carolina \\ Abstract of Paper Proposed for the \\ 32nd AIAA Thermophysics Conference \\ June 23-25, 1997 \\ Atlanta, Georgia
}

\section{Introduction}

Aerobraking has been proposed as an efficient means of decelerating spacecraft for planetary missions. ${ }^{1}$ Most current aerobrake designs feature a blunt forebody shielding the payload from the intense heat generated during atmospheric entry. Although this forebody will absorb the largest portion of the heat pulse, accurate prediction of heating in the near wake is of great importance, since large local heating values can occur at points of shear-layer impingement. ${ }^{2}$

In order to address the various issues associated with these blunt-body wake flowfields, the Advisory Group for Aerospace Research and Development (AGARD) formed Working Group 18 in 1992. One of the objectives of this activity was to examine real-gas effects in high-speed flowfields around a $70^{\circ}$ blunted cone; the primary dimensions of this geometry are shown in Fig. 1. To date, many researchers have conducted experiments using this geometry in various facilities, such as the Large Energy National Shock (LENS) tunnel at Cubric/Calspan ${ }^{3}$ and the HEG shock tunnel at DLR-Göttingen. ${ }^{4}$ Several computational studies have also been conducted in concert with these tests. 5.6

Many of the experimental results have indicated the possible presence of a transitional shear layer through a large increase in heat transfer downstream of the reattachment point. The presence of transition could in fact lead to much higher peak heating than if the separated flow is entirely laminar or turbulent. ${ }^{7}$ In the shock-tunnel tests, however, it is difficult to separate such viscousflow phenomena from real-gas effects. In order to help make this distinction, Horvath et al. recently conducted a set of experiments in the NASA Langley 20-Inch Mach 6 Tunnel, and compared the results to laminar Navier-Stokes calculations. ${ }^{8}$ They found heat-transfer distributions similar to those obtained in the high-enthalpy facilities, with the measured peak heating along the sting support markedly greater than that predicted by the laminar computations. These trends point to the need to find transitional and turbulent computational solutions for these flowfields.

* Research Assistant, Mechanical and Aerospace Engineering. Student Member AIAA.

$\dagger$ Aerospace Technologist, Aerothermodynamics Branch, Aerodynamics and Gas Dynamics Division, Member AIAA.

$\doteqdot$ Professor, Mechanical and Aerospace Engineering. Associate Fellow AIAA. 
The objective of this work is to assess the requirements for transition and turbulence modeling in blunt-body wake flows.

\section{Present Approach}

Our approach relies on the implementation of appropriate transition and turbulence closure models in the nonequilibrium flow solver developed by Olynick. ${ }^{9}$ This is a 5 -species, 3-temperature algorithm for the full Navier-Stokes equations. It utilizes Roe's invscid flux-difference splitting ${ }^{10}$ with variable extrapolation for high-order extension, and the LU-SGS diagonal implicit algorithm of Yoon ${ }^{11}$ for time integration. An attractive feature of this implicit method is that the computational expense associated with the method increases only linearly with the number of partial differential equations being solved.

In order to include the influence of turbulent fluctuations in the algorithm, the conservation equations are averaged using the standard Favre-averaging technique, giving rise to additional unkowns commonly referred to as the Reynolds stresses and Reynolds heat flux. These terms are modeled using Boussinesq's approximation, so that

$$
\begin{gathered}
-\overline{\rho u_{i}^{\prime \prime} u_{j}^{\prime \prime}}=\mu_{t}\left(\frac{\partial \tilde{u}_{i}}{\partial x_{j}}+\frac{\partial \tilde{u}_{j}}{\partial x_{i}}-\frac{2}{3} \delta_{i j} \frac{\partial \tilde{u}_{m}}{\partial x_{m}}\right)-\frac{2}{3} \delta_{i j} \rho \tilde{k} \\
\overline{\rho u_{j}^{\prime \prime} h^{\prime \prime}}=-\lambda \frac{\partial \tilde{T}}{\partial x_{j}}
\end{gathered}
$$

where the overbars indicate time-averaged quantities, the tildes denote Favre-averaged quantities, the double primes indicate fluctuations, and $\tilde{k}=\frac{1}{2} u_{i} \tilde{u}_{i}$ is the turbulent kinetic energy. The turbulent transport properties are assumed to be functions of turbulent length scales, as well as the turbulent kinetic energy. Separate length scales are used to define the turbulent viscosity and thermal conductivity, leading to a variable turbulent Prandtl number. Evolution of the turbulent kinetic energy is presently governed by a single additional partial differential equation, discussed in Ref. 12.

This one-equation model is augmented by a high-speed transition model due to Warren et al. ${ }^{13}$ The transition model incorporates first-mode disturbance scales extended to compressible flows using the reference temperature method, as well as second-mode disturbance scales often present in supersonic flowfields.

\section{Results}

Preliminary results for a freestream Mach number of 6 and a freestream Reynolds number of 2 million have been obtained on the $125 \times 90$ grid shown in Fig. 2; because of the relatively low freestream Mach number and the desire to separate viscous effects from real-gas effects, chemical reactions are disabled for these computations. Figs. 3 and 4 compare numerical heat-transfer results for both laminar and transitional solutions to experimental data from Ref. 8 for this flow condition. Note that the transition point was chosen based on the location of the increase in the experimental heat-transfer rate. The forebody results in Fig. 3 show very good agreement with the experimental data. However, in Fig. 4, it is evident that there is a substantial discrepancy between the predicted heating values and the experimental measurements. Most importantly, the transi- 
tional calculation does not show nearly as large a heating rise as is seen in the experimental data. All available transition models, including that developed in Ref. 13, address transition in one shear layer and all require a specification of a transition onset location. The wake flow of a body mounted on a sting is characterized by the interaction of a free shear layer and the sting boundary layer. Based on the experimental data presented in Ref. 8, transition is taking place within the shear layer. Thus, specifying a transition point on the sting is not going to produce an accurate description of the flowfield in the wake region. Therefore, existing transition models are incapable of handling such flows.

\section{Future Work}

We plan the implementation of a newly developed transition model ${ }^{14}$ that determines transition onset in the flow as part of the solution. Further, the model is complete in the sense that no length scales need to be specified. All it requires are initial and boundary conditions.

\section{Acknowledgments}

This work is supported in part by NASA's Cooperative Agreement NCC1-112. One author (R. P. N.) acknowledges the support of a Graduate Assistance in Areas of National Need (GAANN) Fellowship in Computational Engineering and Science. Computational resources are provided by the North Carolina Supercomputing Center.

\section{References}

1. Tauber, M., Chargin, M., Henline, W., Chiu, A., Yang, L., Hamm, K. R., Jr., and Miura, H., "Aerobrake Design Studies for Manned Mars Missions", Journal of Spacecraft and Rockets, Vol. 30, No. 6, November-December 1993, pp. 656-664.

2. Gnoffo, P. A., Price, J. M., and Braun, R. D., "Computation of Near-Wake, Aerobrake Flowfields", Journal of Spacecraft and Rockets, Vol. 29, No. 2, March-April 1992.

3. Holden, M., Kolly, J., and Chadwick, K., "Calibration, Validation and Evaluation Studies in the LENS Facility", AIAA Paper 95-0291, January 1995.

4. Kastell, D., Horvath. T. J., and Eitelberg, G., "Nonequilibrium Flow Expansion Experiment Around a Blunted Cone", Proceedings of the Second European Symposium on Aerothermodynamics for Space Vehicles, ESA SP-367, February 1995.

5. Gochberg, L. A., Allen, G. A., Jr., Gallis, M. A., and Deiwert, G. S., "Comparison of Computations and Experiments for Nonequilibrium Flow Expansions Around a Blunted Cone", AIAA Paper 96-0231, January 1996.

6. Muylaert, J., Walpot, L., Spel, M., Tumino, G., and Steijl, R., "Non Equilibrium Computational Analysis of Blunt-Cone Experiments Performed in the LENS and HEG Facilities", AIAA Paper 96-2436, June 1996.

7. Baker, P. J., and Martin, B. W., "Heat Transfer in Supersonic Separated Flow over a TwoDimensional Backward-Facing Step", International Journal of Heat and Mass Transfer, Vol. 9, 1966, pp. 1081-1088.

8. Horvath, T. J., McGinley, C. B., and Hannemann, K., "Blunt Body Near Wake Flow Field at Mach 6", AIAA Paper 96-1935, June 1996. 
9. Olynick. D. P., and Hassan, H. A., "A New Two-Temperature Dissociation Model for Reacting Flows", Journal of Thermophysics and Heat Transfer, Vol. 7, No. 4, October-December 1993, pp. 687-696.

10. Roe, P. L., "Approximate Riemann Solvers, Parameter Vectors and Difference Schemes", Journal of Computational Physics, Vol. 43, 1981, pp. 357-372.

11. Yoon, S., and Jameson, A., "An LU-SSOR Scheme for the Euler and Navier-Stokes Equations", AIAA Paper 87-0600, January 1987.

12. Gaffney, R. L., Jr., Salas, M. D., and Hassan, H. A., "An Abbreviated Reynolds Stress Model for Airfoil Flows", AIAA Paper 90-1468, June 1990.

13. Warren, E. S., Harris, J. E., and Hassan, H. A., "Transition Model for High-Speed Flow", AIAA Journal, Vol. 33, No. 9, August 1995, pp. 1391-1397.

14. Warren, E. S., and Hassan, H. A., "An Alternative to the $e^{n}$ Method for Determining Onset of Transition", AIAA Paper 97-0825, January 1997. 
WFigures

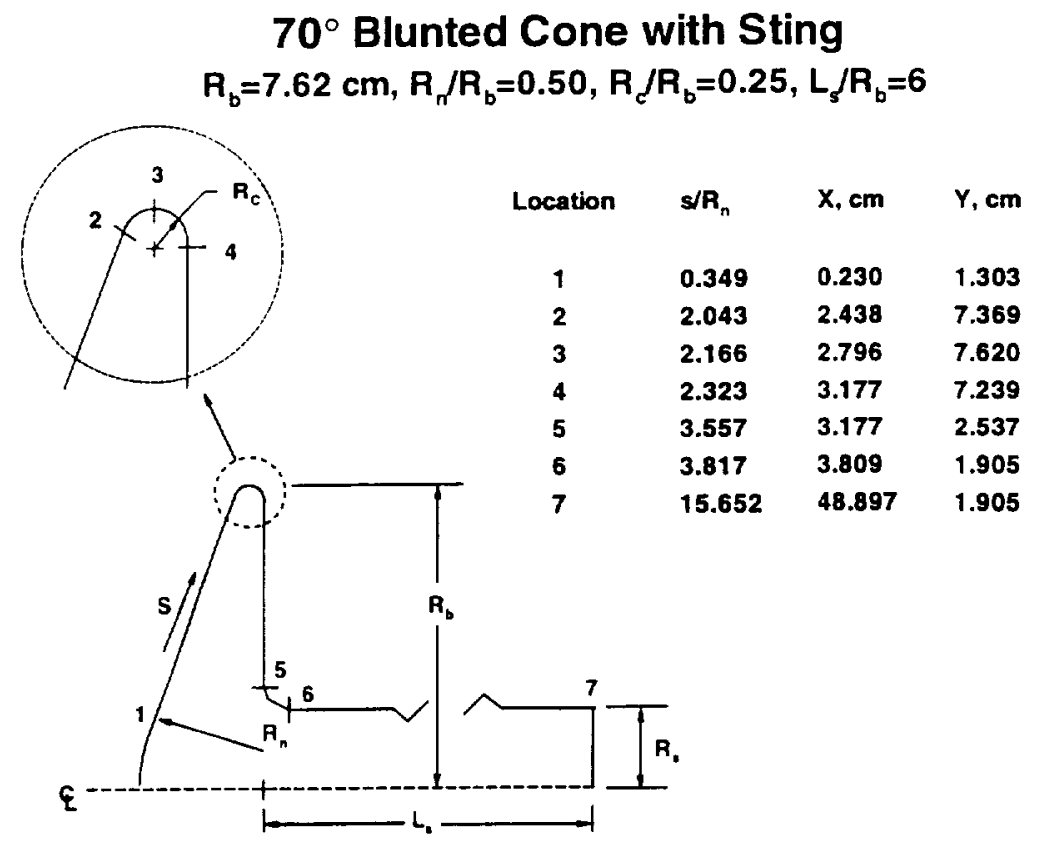

Figure 1. Blunted-cone geometry

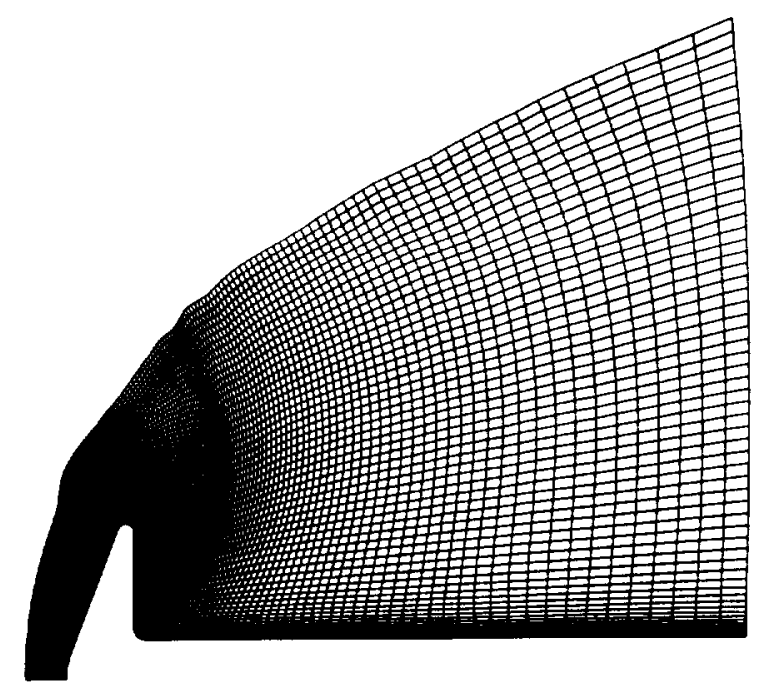

Figure 2. Grid for Navier-Stokes calculations 


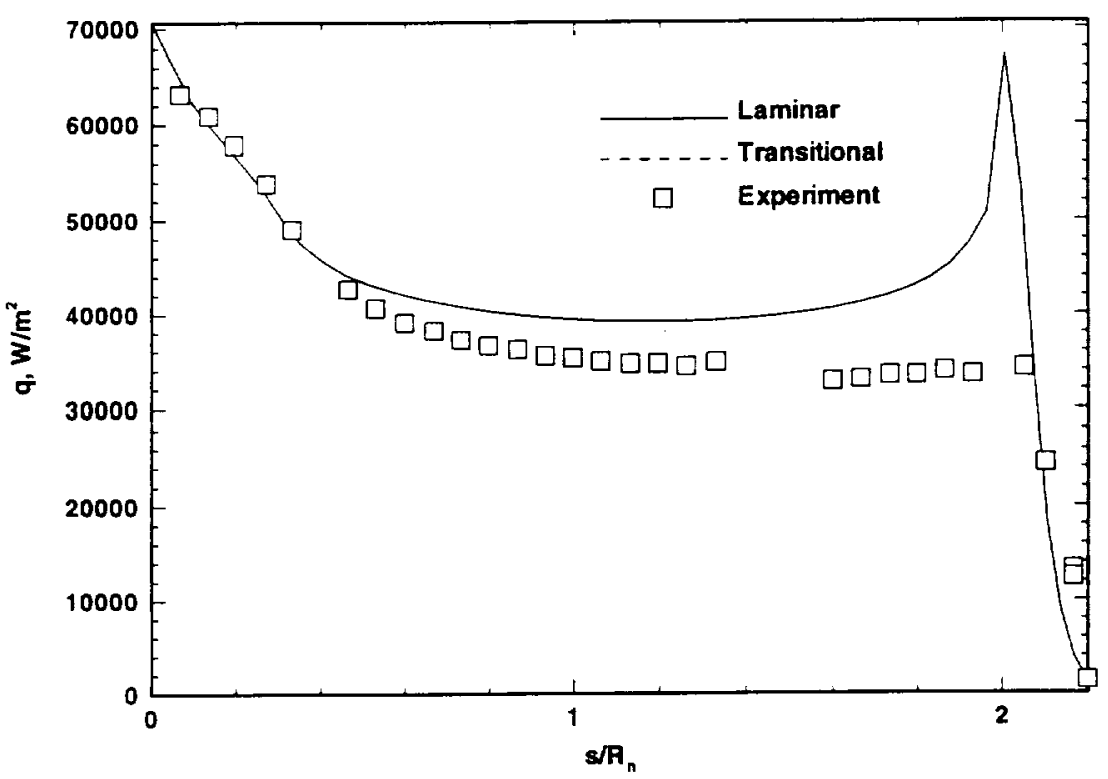

Figure 3. Forebody heat-transfer results

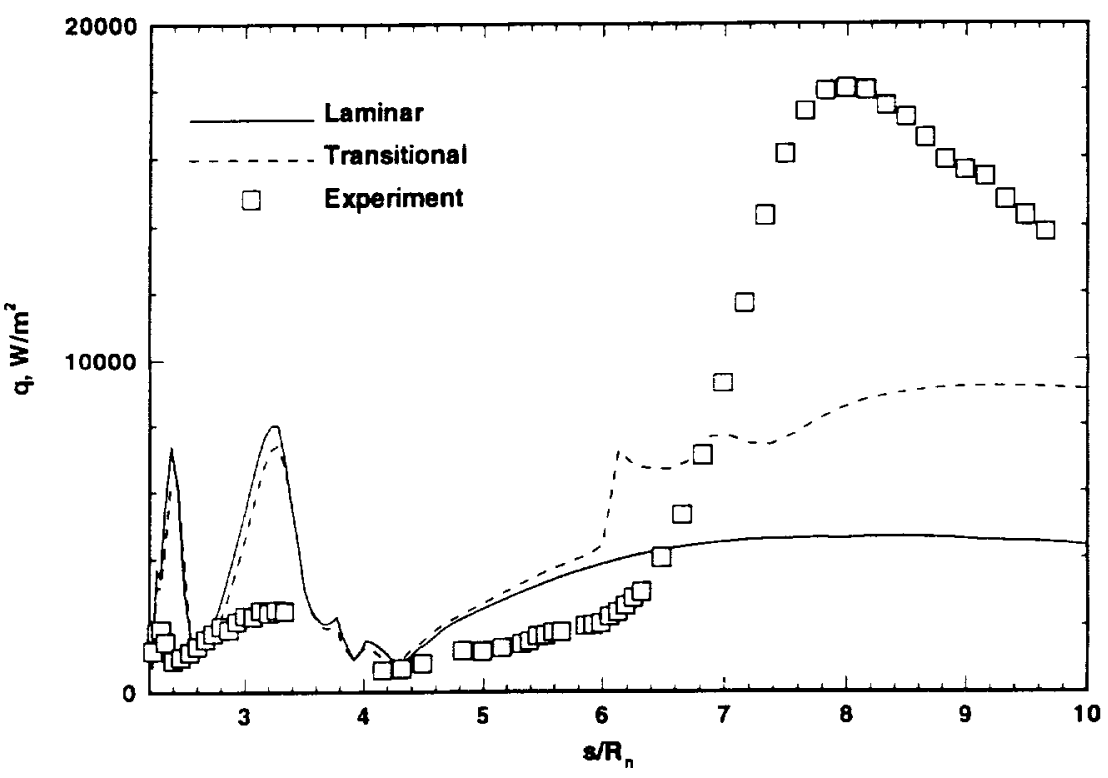

Figure 4. Back plane and sting heat-transfer results 